Revista Iberoamericana. Vol. LXIV, Núms. 182-183, Enero-Junio 1998; 229-239

\title{
O DIÁLOGO BRASIL/AMÉRICA HISPÂNICA \\ NA CRÍTICA DE SILVIANO SANTIAGO E OCTAVIO PAZ
}

\author{
POR \\ Ivete Lara Camargos Walty \\ Pontificia Universidade Católica, Minas Gerais
}

Ao visitar o Memorial da América Latina em São Paulo, chamou-me atenção, no pavilhão mexica/no, a profusão de alegorias, máscaras da morte, misto de tristeza e alegria, luto e cores. Naquele momento, (1990) reportei-me à obra de Octavio Paz e sua busca de definição da mexicanidade, sobretudo no que se refere ao livro Labirinto da solidão e post-scriptum, onde usa a figura da máscara para refletir sobre a identidade do povo mexicano.

Na mesma ocasião, trabalhando com narrativas de índios brasileiros, valia-me dos estudos de Silviano Santiago para pensar a questão da colonização em seu jogo de espelhos, a refletir a face do colonizado e do colonizador.

Tanto o crítico mexicano quanto o brasileiro, num primeiro momento, reconhecem $o$ aspecto especular da colonização, na medida em que o colonizador imporia ao habitante da terra americana o rosto europeu. Assim as figuras do espelho e da máscara, associadas à idéia de representação, de duplicação da imagem falam de uma analogia implícita no processo da colonização. Nessa vertente impõe-se o jogo analógico, que implica nas noções de cópia e modelo, de aparência e essência. Mas os críticos citados, ao evidenciar esse jogo especular, ultrapassam-no, deixando entrever outra função do espelho, a refração, que, ao invés de fazer convergir os raios de luz, espalha-os, disseminando a imagem, fragmentando-a.

A partir do estudo da recorrência de tais imagens na obra dos dois críticos, gostaria de examinar como é tratada a questão da identidade da literatura latino-americana. Não tenho como objetivo cotejá-los, criticando-os ou louvando-os. Antes pretendo rastrear o percurso de suas leituras, situando-as nessa discussão sobre o lugar latino-americano, sem me abster de também me situar enquanto leitora latino-americana. Isso porque, cada vez mais, se percebe que o ato de ler determina a postura teórica e a define. De toda teoria da literatura pode-se depreender uma teoria da leitura.

Em trabalho anterior, retomei o que seria o percurso desse movimento em parte da ficção latino-americana que tinha o índio como objeto - Alencar, Darcy Ribeiro, Vargas Llosa - e da crítica brasileira presa ao dualismo modelo e cópia - Afrânio Coutinho, Nelson Werneck Sodré, Roberto Schwarz-e a tentativa de superação desse 
dualismo - Antonio Candido, Silviano Santiago, Haroldo de Campos, relacionandoos, vez por outra, com outros críticos latino-americanos, inclusive Paz. O que pude concluir à época foi que "os dois pólos continuam marcando não apenas a literatura brasileira e latino-americana, mas a crítica brasileira, seja para sua afirmação ou para sua negação" (Walty 112). E, ao preconizar que a literatura brasileira ou toda a literatura latino-americana deveria resgatar seu lado índio, "como forma de explicitação daquilo que foi jogado debaixo do tapete para não ser visto pelas visitas, reinstaurando a possibilidade da troca simbólica", mantenho-me na eterna questão do nacional X universal. Encerro o texto, afirmando: "Dessa forma não se precisa esperar o país mudar para se falar de Literatura Nacional, repetindo a idéia de que o bolo precisa crescer para ser repartido" (119).

Vale, pois, refletir sobre a permanência dessa leitura na crítica latino-americana, situando-a no âmbito da leitura moderna face às mudanças operadas por uma postura dada como pós-moderna.

Diz Compagnon, discutindo os cinco paradoxos da modernidade:

A história moderna narra a si mesma com vistas ao desfecho a que quer chegar; não aprecia os paradoxos que escapam à sua intriga e os resolve ou os dissolve em desenvolvimentos críticos; ela se escreve a partir dos conceitos combinados de tradição e ruptura, de evolução e de revolução, de imitação e de inovação (111).

Dessa forma, pode-se constatar que o movimento pendular que acompanha a discussão da formação das literaturas colonizadas é antes provocado pela leitura baseada em parâmetros da modernidade que se faz do fenômeno, que englobaria a angústia da influência, a busca da inovação em relação ao modelo proposto ou imposto, a oscilação entre o nacional e o universal.

Observe-se que a imagem do espelho pode condensar vários elementos desse processo. O espelho expressa, como já se afirmou, em primeiro lugar, as correspondências analógicas, na medida em que projeta e reduplica a imagem. Há muito se sabe que colonizar é, antes de tudo, reduplicar, fazendo permanecer o mesmo. A história da colonização assim contada, na perspectiva do colonizador, faz-se espelho a multiplicar sua imagem.

No entanto, o espelho, ao refratar a imagem, devolvendo-a fragmentada, espraiada, associa-se à ironia e à ruptura. Assim o texto da colonização ou o texto que hoje se escreve sobre ela é espelho, na medida em que o autor, ao escolher seus objetos para construir o relato, fruto por sua vez do recorte, da moldura que dirige e limita sua observação, rejeita aquilo que não é capaz de perceber ou considera desprezível. Ocorre, entretanto, que o recalcado retorna nas franjas do discurso, permitindo-nos ver além do horizonte vislumbrado pelo crítico ou pelo historiador (De Certeau 16).

Dessa forma os narradores constróem sua imagem do processo, mas esse retrato se faz espelho e, através da imagem distorcida aí contida, vê-se a outra imagem daqueles que contam a história. Se se toma, por exemplo, o caso do índio como 
habitante da terra, vê-se que também ele é espelho enquanto imagem refletida do europeu e de sua própria alteridade recalcada, como bem mostra Silviano Santiago ao mostrar a experiência da colonização como:

(...) experiência narcísica, em que o outro, é assimilado à imagem refletida do conquistador, confundido com ela, perdendo portanto a condição única da sua alteridade. Ou melhor, perde a sua verdadeira alteridade (a de ser outro, diferente) e ganha uma alteridade fictícia ( a de ser imagem refletida do europeu). O indígena é o Outro europeu: ao mesmo tempo imagem especular deste e a própria alteridade do indígena recalcada (Vale quanto pesa 15-16).

Também Octavio Paz assim se refere ao processo colonial:

(...) era projeção de uma sociedade que já tinha atingido sua maturidade e estabilidade na Europa. Sua originalidade é escassa. A Nova Espanha não procura, nem inventa: aplica e adapta. Todas as suas criações, inclusive a do seu próprio ser, são reflexos das espanholas (...) (Labirinto 96).

Paz faz coincidir também seu pensamento com o de Silviano quando, citando Zea, define a América como um monólogo da Europa. Observe-se que Silviano mostra a força do signo lingüístico em sua associação com o religioso (Santiago, Uma literatura 16).

Mas os dois críticos apontam também a propriedade refratora do espelho, na medida em que devolve para o colonizador aquilo que recalcou em si mesmo. Paz, ao desenvolver o conceito de outridade, evidencia o estrangeiro que temos em nós mesmos, na medida em que mostra a experiência da outridade como

a percepção de que somos outros sem deixar de ser o que somos e que, sem deixar de estar onde estamos, nosso verdadeiro ser está em outra parte. Somos outra parte (Signos 107).

Silviano fala de como "o signo estrangeiro se reflete no espelho do dicionário e na imaginação criadora do escritor latino-americano e se dissemina sobre a página branca com a graça e o dengue do movimento da mão que traça linhas e curvas" (Santiago, Uma literatura 23). Dessa forma, mais uma vez coincidindo com Octavio Paz e seu conceito de escrita como tradução, fala da importância de uma leitura deslocadora, que seria sempre "tradução global, pastiche, paródia, digressão".

A ponte-se aí um certo apego ao dualismo presente na perspectiva da modernidade, que parece se diluir nos últimos ensaios do crítico brasileiro que, hoje, aponta o pastiche como "mais e mais imitação", enquanto a paródia, seria "mais e mais ruptura". É que , ao desenvolver o conceito de escrita suplemento com que há muito vem trabalhando, Santiago supera o dualismo expresso no par colonizador/colonizado, na medida em que seríamos todos colonizadores e colonizados, entrevistos no jogo de máscaras do 
processo histórico-cultural, que se daria não mais num entre-lugar mas num sobrelugar. Não é sem razão que fala da impossibilidade de se falar de identidade brasileira:

A literatura brasileira de hoje (romance, conto e poesia) é fundamentalmente pessimista em relação aos valores hegemônicos no país e no Ocidente, vale dizer, em relação às possibilidades de articular no presente Arte, Nação e História. Por isso ela abandonou de vez a possibilidade de representar a nação brasileira de forma histórica e global, pois sabe que a atualidade do país é a sua fragmentação em multifacetados grupos sociais, agressivamente subjetivos que não conseguem se articular coletiva e ideologicamente de modo a constituir isso a que chamamos de "brasilidade" ou essa outra coisa ainda mais complexa a que chamamos de "globalização brasileira" ("Brasil" 7).

\section{Ou ainda:}

É inevitável que surjam outras e mais caras alegóricas do Brasil neste tempo de incertezas e precariedades. Por sua vez vez, a literatura se recusa a mostrar uma cara do Brasil com perfil nítido e personagens com percursos biográficos completos. Se ela mostra uma cara do Brasil (e, na realidade, a mostra) é a duma figura humana (?) num quadro de Francis Bacon. Essa cara ficcional e poética do Brasil, se cara for, são antes borrões grotescos, ininteligíveis e farsercos da "brasilidade" ("Brasil" 7).

Ao falar de borrões, reportamo-nos à idéia de máscaras tão utilizada pelos dois autores. Silviano que, antes falava da necessidade de se "liberar a imagem de uma América Latina sorridente e feliz, o carnaval e a fiesta, colônia de férias para o turismo cultural" (Uma literatura 28) hoje reconhece que tudo são máscaras e, acredito, no meio delas, não há espaço apenas para essa imagem idealizada de alegria e festa.

Octavio Paz, por sua vez, em O labirinto da solidão, fala da máscara usada pelo mexicano no trato com os patrões, máscara que traduz um processo de mimetismo, como forma de resistência:

Escravos, servos ou raças submetidas apresentam-se sempre cobertos por uma máscara, sorridente ou austera. Eunicamente a sós, nos grandes momentos, atrevemse a manifestar-se tal como são (67).

Registre-se um certo tom idealista e metafísico que atravessa a obra de Paz, mesmo quando fala explicitamente em descentramento. Em mais de uma vez, ele propõe a existência de uma essência atrás da máscara, até chegar a propor que essa essência é a humana: "A mexicanidade é uma máscara que, ao cair, deixará ver por fim o homem" (152). Ou ainda:

O mexicano se esconde debaixo de muitas máscaras, que em seguida arranca num dia de festa ou de luto, do mesmo modo como a nação arrebentou todas as formas que a asfixiavam. 
[...] Se arrancarmos estas máscaras, se nos abrirmos, se, enfim, nos enfrentarmos, começaremos a viver e pensar de verdade (Labirinto 173).

Em seu ensaio "O poeta, a palavra e a máscara", Celso Lafer, parafraseando Paz, parece constatar o império das máscaras, mas termina por recair no essencialismo da busca de um verdadeiro rosto mexicano, ou melhor, um verdadeiro rosto humano:

Sempre lemos uma tradução e nunca o original pois, atrás das máscaras, não há nada a não ser talvez um nós/outros instantâneo - uma imagem poético-política revelada pela interpretação. Entretando, enquanto vivemos precisamos das máscaras, que são facções e ficções do nosso ser, pois, [...] estamos condenados a inventar uma máscara e descobrir depois que esta máscara é o nosso verdadeiro rosto (272).

Por outro lado, é curioso notar que, ao falar dos astecas, Paz propõe um jogo de espelhamento, de que parece querer se excluir:

Não é um museu, mas sim um espelho - só que nesta superfície tatuada de símbolos não somos nós que estamos refletidos, mas sim contemplamos, agigantado, o mito de México-Tenochtitlán [...]. Neste espelho não nos abismamos na nossa imagem, mas sim adoramos a imagem que nos esmaga (Labirinto 259).

Guardadas as devidas proporções e mesmo sem entrar nas inúmeras diferenças, é fundamental registrar o que nos chama atenção na obra dos dois críticos em relação ao tratamento dado ao índio. Enquanto Silviano, em muitos de seus ensaios busca discutir o lugar dado ao índio pela chamada civilização, repudiando, ao mesmo tempo, a visão eurocêntrica e a visão ufanista, reserva ao colonizador o lugar da violência, como se pode ver sobretudo em "Oswald de Andrade ou: elogio da tolerância étnica"(67-77); o segundo, ao discorrer sobre a diversidade da composição étnica da Mesoamérica, atribui não apenas ao colonizador, mas também aos astecas a violência herdada pelos mexicanos, não para recusá-la, mas para incorporá-la.

Por outro lado, mais recentemente, ao ser indagado sobre a identidade latinoamericana, diz Octavio Paz:

No me gusta la palabra identidad. Aún menos la frase de moda "búsqueda de la identidad". Lo que llamamos identidad y que antes, con mayor propiedad, se llamaba el carácter, el alma o el genio de los pueblos, no es una cosa que se pueda tener, perder o recobrar. Tampoco es una sustancia ni una esencia. América Latina no es ni un ente ni una idea. Es una historia, un processo, una realidad en perpetuo movimento y cambio continuo. América Latina existe en la historia o, más bien, es historia (...) No es fácil definirla y ni siquiera describirla (Vuelta 195,30$)$.

Nota-se aí, a tentativa de relativização do próprio conceito de América Latina e, a despeito da utilização da palavra alma, muito significativa, uma busca de superação 
da tendência metafísica, na conclusão de que não se pode falar de essência mexicana ou mesmo humana, já que a identidade é antes processo.

Assinale-se, pois, uma trajetória com alguns pontos em comum dos dois críticos que, ora, mesmo buscando superar o dualismo, aí se mantém em virtude do tipo de leitura feita baseada em parâmetros da modernidade; ora, percebem de fato a fluidez do processo e a impossibilidade de se falar de uma identidade constituída por oposição àquela do colonizador. O retrato faz-se borrão, a máscara se consagra como máscara, de qualquer forma, incitando sempre a troca simbólica.

Vale, ainda, investigar o que estou chamando de parâmetros de modernidade da leitura ligada ao colonialismo ou neocolonialismo por oposição ao que seria uma leitura pós-moderna ditada por teorias pós-coloniais, sem, no entanto estar falando de leituras circunscritas a um tempo cronológico linear. Para tal faz-se necessário discutir os conceitos de tradição e ruptura na obra dos dois autores, que mantêm, na verdade, um diálogo explícito sobre o assunto.

Silviano Santiago, ao examinar o que seria "a permanência do discurso da tradição no modernismo", retoma o conceito de "tradição da ruptura" usado por Octavio Paz, e afirma:

Paz define duas formas de tradição: a tradição da ruptura, esta a que me referi anteriormente, como sendo a do "Make-it-new" glorioso, e a tradição da analogia. A aproximação crítica das duas formas de tradição nunca chega a emergir no raciocínio ou no texto de Paz. Eis um livro a ser feito que investigaria o papel da tradição da analogia ao lado, ou mesmo dentro, da tradição da ruptura, enquanto articuladores do pensamento moderno (Nas malhas 97).

Maria Esther Maciel, em seu estudo sobre Octavio Paz, discorda do crítico brasileiro e seu trabalho como um todo abaliza sua discordância, já que, relacionando a obra de Paz com as gravuras de Escher, mostra como aquele trabalha com a disjunção e a conjunção enquanto duas faces de uma mesma moeda. A despeito de certa generalização do que seria o procedimento constelar adotado por Paz, muitas vezes mais fruto da leitura feita pela estudiosa do que da proposta do crítico, há que se perceber que, analogia e ironia aproximam-se, constantemente num jogo de gato e rato, onde, mesmo quando uma tenta se impor, a outra se faz mostrar.

Por outro lado, Silviano, ao discutir o conceito de tradição da ruptura, parece se fixar na leitura linear da expressão em que se vê a ruptura firmar-se como tradição. Compagnom reconhece tal sentido, mas explicita mais amplamente a contradição da expressão:

Falar de tradição moderna seria, pois, um absurdo, porque essa tradição seria feita de rupturas. É verdade que essas rupturas são concebidas como novos começos, invenções de origens cada vez mais fundamentais; logo, porém, esses novos começos terminam e essas novas origens deverão ser imediatamente ultrapassadas. Na medida em que cada geração rompe com o passado, a própria ruptura constitui a tradição. Mas 
uma tradição da ruptura não é, necessariamente, ao mesmo tempo uma negação da tradição e uma negação da ruptura? (10, grifos meus).

Ao se fazer tal pergunta, Compagnon retoma Octavio Paz realçando o que chama de aporia ou impasse lógico da aliança dos contrários. Por outro lado, como se pode ver pelo que foi dito até agora, o próprio Silviano há muito vem fazendo o "livro" que diz precisar ser feito, que "investigaria o papel da tradição da analogia ao lado, ou mesmo dentro, da tradição da ruptura, enquanto articuladores do pensamento moderno" (Nas malhas 97).

Vale, pois, investigar como se associam na obra dos dois poetas e críticos essas duas tradições, ou melhor, essa tradição paradoxal que traz em si a ruptura, ou que associa analogia e ironia. Tradição essa que está presente na teoria do entre-lugar, proposta pelo crítico brasileiro, na medida em que:

Entre o sacrifício e o jogo, entre a prisão e a transgressão, entre a submissão ao código e a agressão, entre a obediência e a rebelião, entre a assimilação e a expressão, —ali, nesse lugar aparentemente vazio, seu templo e seu lugar de clandestinidade, ali, se realiza o ritual antropófago da literatura latino-americana (Santiago, Uma literatura 28).

A leitura atenta de Octavio Paz apontará para a presença dessas mesmas palavras: jogo, sacrifício, rebelião, revolução, clandestinidade ou marginalidade, ausência de centro, antropofagia, vazio. Silviano Santiago e Octavio Paz fariam, então, uma leitura que, na busca da nacionalidade, tentaria superar o dualismo decorrente da submissão a um cânone externo, fruto por sua vez de uma concepção linear da história. No artigo "Octavio Paz: ruptura e convergência", Maria Esther Maciel aponta para esse mesmo percurso entrecruzando-o com o do crítico Haroldo de Campos. É assim que ela afirma que

Ambos vêem na poesia de ruptura a literatura de fundação da América Latina e adotam o método da história sincrônica para trabalhar o entrecruzamento de linguagens e tradições na literatura ocidental (Maciel 141).

Observe-se a contradição expressa ao se falar de literatura de fundação e ruptura, literatura de fundação e história sincrônica, já que fundação implica em origem. Assim sendo a origem só poderia ser a ruptura, o vazio.

Mais adiante Maciel estende essa aproximação aos poetas críticos do Ocidente, mostrando como a reflexão sobre o entrecruzamento de linguagens e tradições foi inaugurada pelos românticos alemães e consolidada por Baudelaire, Mallarmé, Valéry, Pound e Eliot, dentre outros. Tradição que, na América Latina, comporta eminentes representantes como Mário e Oswald de Andrade, Borges, João Cabral, Lezama Lima (Maciel 143). Não por coincidência os trabalhados por Silviano Santiago em seu ensaio sobre a permanência da tradição no modernismo. 
O estudo de outros críticos, poetas ou não, da América Latina, como Edouard Glissant podem nos mostrar a permanência da busca de superação das fronteiras na constituição da identidade. Glissant nos fala da passagem de uma poética do retour para uma poética do detour, também ele, buscando superar o simplismo da volta às raízes, propondo uma poética da relação. E é ele mesmo que propõe ainda uma poética do caos-mundo, onde postula a convivência com a opacidade do outro ao invés da busca de torná-lo transparente para compreendê-lo: com - preendre - tomar sob o jugo de. A noção de espaço gnóstico de Lezama Lima também vem construir a expressão americana "com uma infinitude de imagens, pelo descolamento contínuo dos significantes, pelos efeitos de refração e reverberação da idéia" (Fonseca et al. 178).

As autoras mostram ainda como também Alejo Carpentier apresenta o real maravilhoso como um processo perceptivo hábil para apreender as ambigüidades e as metamorfoses da realidade americana, insistindo na ação realizada pelo olhar, que se quer componente da realidade apreendida.

Os termos e expressões "opacidade", "transparência", "efeitos de refração e reverberação", "ação realizada pelo olhar", entre outros estão implícitos nas imagens do espelho e da máscara e ligam-se inevitavelmente às figuras da analogia e da ironia, também usadas por Paz para trabalhar a questão da modernidade. Pode-se perguntar, portanto, qual o uso que a crítica latino-americana faz dos paradoxos da modernidade em sua discussão da formação da identidade desse povo.

O estudo da obra de Silviano Santiago e Octavio Paz nos deixa entrever ainda a relatividade dos conceitos de civilização e barbárie e, conseqüentemente, a relatividade do conceito de progresso, o que por sua vez integra uma discussão que remonta a Baudelaire, passando por Nietzsche e Benjamin. Nesse momento em que essas questões retornam no bojo da globalização, faz-se mister pensá-las mais uma vez. Nossos presidentes estão preocupados em fazer o país entrar nos trilhos do que chamam também modernidade e, para isso, propõem desenvolver a indústria, acelerar as importações, talvez, para que o povo deixe de ser "caipira". Paz já assinalara que, correndo atrás do progresso, estaríamos disputando o privilégio de chegar primeiro ao inferno. É que o progresso do continente não anda associado ao desenvolvimento de seu povo já que também seu modelo é ditado pelos povos dados como desenvolvidos. Também aí o parâmetroé externo e único: progredir é desenvolver-se tecnologicamente, mesmo que à custa do maior segmento da população.

Os críticos latino-americanos - Antonio Candido, Haroldo de Campos, Silviano Santiago e o próprio Paz - vêm refletindo sobre a relação entre subdesenvolvimento e autonomia literária, desvinculando o processo cultural do econômico. De qualquer maneira, mantém-se até aí a preocupação dualista: nacional X universal. O que me parece mais importante no momento é justamente tentar detectar porque pensamos insistentemente nesse processo e no lugar que ocupamos nele. Estaríamos hoje tentando entrar na modernidade no plano econômico, quando já atingimos o pensamento pós-moderno, no plano teórico-reflexivo? Ou justamente, tudo depende da camada a que se refere, já que temos Brasis, Méxicos e Américas Latinas. Por outro lado, o que é o pós-moderno e qual a sua relação com o moderno? 
Se o jogo entre cópia e modelo, tradição e ruptura é próprio da modernidade, por que se fala de uma crítica latino-americana em busca de identidade de sua literatura? Se a questão do outro nasceu com a antropologia e com a etnologia, talvez, como acentua Silviano Santiago, como resultado da má consciência européia, por que a incorporamos em nosso discurso? Se o processo de colonização é a tentativa de fazer prevalecer o mesmo e se espalha dentro da própria sociedade colonizada, de que lado está o diferente? Se os limites entre modernidade e pós-modernidade são, na verdade, tão fluidos, de que lugar fala o intelectual latino-americano? Não seria o pós-moderno justamente um suplemento do moderno, que permite reescrevê-lo, deslocando-o?

Essas e outras perguntas poderiam se encadear num movimento infinito e é justamente isso o que ocorre na construção da literatura latino-americana em sua relação com a crítica. As perguntas que esta se faz não são diferentes das perguntas que os outros se fazem. Mas, num jogo de conjunção e disjunção, perguntas e respostas vão se relativizando de um lado e outro do planeta. Não é, pois, sem razão que a crítica latino-americana se apropria do paradoxo da modernidade para ler sua cultura em relação com as outras, explicitando contradições que uma leitura autoritária insistiria em esconder. Na verdade, essas perguntas são movidas pelo desejo de identidade que move todos os povos: só o desejo nos faz nós mesmos, conforme mostra Bhabha. É, pois, no desejo que a literatura latino-americana se constrói, é no desejo que a crítica se constrói e, por isso mesmo, a teoria deixa escapar sonhos e idealismos, utopias e analogias, ao mesmo tempo em que revela a ironia e a crítica com o outro e consigo mesma. Tudo é uma questão de leitura: colonialismo, neocolonialismo, póscolonialismo, jogo de olhares, espelhos e máscaras. E é nesse jogo de leituras que se escreve/inscreve o texto latino-americano, também ele espelho em seu diálogo com outros textos e outras culturas, superando geografias.

\author{
Me vejo no que vejo \\ Como entrar por meus olhos \\ Em um olho mais límpido \\ Me olha o que eu olho \\ é minha criação \\ Isto que vejo \\ Perceber é conceber \\ Águas de pensamentos \\ Sou a criatura \\ Do que vejo \\ (Octavio Paz)
}

O crítico mexicano afirma e atesta que um povo se dá a conhecer através de suas criações: "o que nos pode diferenciar do resto dos povos não é a sempre duvidosa originalidade de nosso caráter — fruto, talvez, das circunstâncias sempre mutantes- 
mas sim de nossas criações" (Labirinto 14). No entanto, já sabemos, que não se pode falar de uma originalidade dessas criações, ou de fronteiras rígidas que as delimitem a territórios nacionais, como reconhece o próprio Paz, mais recentemente, ao caracterizar a América Latina como uma realidade verbal:

América Latina es una cultura. No es fácil definirla y ni siquiera describirla. Los que han expresado mejor esa realidad elusiva han sido los escritores. Pero ninguno de esos poemas y novelas es ni puede ser un retrato realista; todas esas obras son imágenes o, más exactamente, imaginaciones de lo que somos (Vuelta 195, 30).

Ingenuidade seria, por outro lado, colocar tudo no mesmo bojo, numa sociedade discriminadora que se utiliza de rótulos para manipulações em defesa de interesse de grupos. Estamos aqui reunidos em nome de uma sociedade de estudos latinoamericanos, somos latino-americanos, não há, pois, como fingir, por mais complexas que sejam essas denominações, ou por isso mesmo, que somos todos um mesmo povo, pois como diz Costa Lima, citando Wlad Godzich, quando discute a necessidade de se passar de um sujeito individual identificável com o sujeito nacional a uma concepção plástica do sujeito:

Em suma, não se trata de repudiar o essencialismo porque particularista ou porque politicamente comprometido. O elogio da heterogeneidade também supõe o privilégio de uma particularidade. Mas de uma particularidade plural e não da que unifica sob o manto do Estado-nação (Costa Lima, "Literatura e nação" 39).

E ainda;

A tão propalada globalização do mundo, na verdade equivalente à centralização do poder em algumas instituições bancárias, é contemporânea à redução do poder dos Estados-nacionais. Isso, por um lado, se correlaciona à reconhecida perda de prestígio da literatura. Por outro, entretanto, permitiria que se repensasse a literatura fora de caminhos que foram traçados a partir de uma conjuntura já não existente [...] (39).

Costa Lima, apesar de apontar que o critério de nacionalidade não é mais fecundo para o estudo das literaturas, pois não se pode mais falar de um sujeito individual ligado ao Estado-nação, ressalta a importância de se criar o hábito da reflexão e de se construir o próprio pensamento teórico ("Antropofagia" 62-75). Construir o próprio pensamento teórico ou participar da rede dialógica da produção cultural que atravessa os países?

Pois bem, Silviano Santiago e Octavio Paz são críticos latino-americanos. E, ao lado de Costa Lima e outros, participam desse diálogo que se trava dentro e fora desse espaço denominado América Latina, que é um elemento de nossa identificação. Afinal, podemos pluralizar a afirmação de Silviano Santiago: "Sou espelho do que me liberta e me aprisiona". 


\section{OBRAS CITADAS}

Bhabha, Homi. Nation and narration. London: Routledge, 1990.

Compagnon, Antoine. Os cinco paradoxos da modernidade. 1990. Trad. Cleonice Mourão et al. Belo Horizonte: Editora da UFMG, 1996.

Costa Lima, Luiz. "Antropofagia e controle do imaginário". Revista Brasileira de Literatura Comparada 1 (Niterói, 1991): 62-75.

"Literatura e nação: esboço de uma releitura". Revista Brasileira de Literatura Comparada 3 (Rio de Janeiro, 1996): 33-40.

De Certeau, Michel. A escrita da história. 1975. Trad. Maria de Lourdes Menezes. Rio de Janeiro: Forense Universitária, 1982.

Fonseca, Maria Nazareth R. et Walty, Ivete. "Teoria da literatura e interdisciplinaridade, o espaço da impureza". Revista de estudos da literatura.4 (Belo Horizonte, CEL/ FALE/UFMG, out. 1996): 171-184.

Lafer, Celso. "O poeta, a palavra e a máscara - sobre o pensamento político de Octavio Paz”. Paz, Octavio. Signos em rotação. Trad. Sebastião Uchoa Leite. São Paulo: Perspectiva, 1976.

Maciel, Maria Esther. Vertigens da lucidez. São Paulo: Experimento, 1995. "Octavio Paz: ruptura e convergência". Maria Zilda Cury e Graça Paulino, orgs. Ensaios de semiótica 26 (Belo Horizonte, 1992-93): 134-145.

Paz, Octavio. Signos em rotação. 1964. Trad. Sebastião Uchoa Leite. São Paulo: Perspectiva, 1976.

O labirinto da solidão e post-scriptum. 1950. Trad. Eliane Zagury. Rio de Janeiro: Paz e Terra, 1984.

Os filhos do barro. 1974. Trad. Olga Savary. Rio de Janeiro: Nova Fronteira, 1984.

A outra voz. 1990. Trad. Wladir Dupont. São Paulo: Siciliano, 1993. “América en plural y singular —el baile de los mascarados". Sérgio Marras: entrevista con Octavio Paz. Vuelta 194 (janeiro de 1993): 11-16. "América en plural y singular - Los nacionalismos y otros bemoles". Sérgio Marras: entrevista con Octavio Paz. Vuelta 195 (fevereiro de 1993): 26-30.

Santiago, Silviano. Uma literatura nos trópicos. São Paulo: Perspectiva, 1978. Vale quanto pesa. Rio de Janeiro: Paz e Terra, 1982. Nas malhas da letra. São Paulo: Companhia das Letras, 1989. Viagem ao México. Rio de Janeiro: Rocco, 1995. "Brasil, mostra a tua cara". Jornal do Brasil (20 abr. 1996A): 7. "Oswald de Andrade ou: elogio da tolerância". Anais do Congresso ABRALIC Literatura e memória cultural. (Belo Horizonte, 1991): 67-77.

Walty, Ivete. "Cópia ou ruptura: um movimento pendular". Maria Zilda Cury e Graça Paulino, Ensaios de semiótica 26 (Belo Horizonte, 1992-93): 98-106. 
